\title{
Phase formation and dielectric properties of Ba0.5Sr0.5TiO3 by slow injection sol-gel technique.
}

\begin{abstract}
A simple sol-gel process incorporating slow precursor injection technique was employed to synthesize homogeneous $\mathrm{Ba} 0.5 \mathrm{Sr} 0.5 \mathrm{TiO} 3$ nano powders. The $\mathrm{Ba} 0.5 \mathrm{Sr} 0.5 \mathrm{TiO} 3$ samples were subjected to calcination temperatures from 600 to $1,100{ }^{\circ} \mathrm{C}$ and sintering temperatures from 1,250 to $1,350{ }^{\circ} \mathrm{C}$ for the study of phase formation, crystallite size, particle distribution, and dielectric properties. Single phase $\mathrm{Ba} 0.5 \mathrm{Sr} 0.5 \mathrm{TiO} 3$ with a cubic perovskite structure was successfully synthesized after calcination at $800{ }^{\circ} \mathrm{C}$. The average size of the nano particles is $42 \mathrm{~nm}$ with a narrow size distribution, and a standard deviation of $10 \%$. The highest values recorded within the investigated range for dielectric constant, and dielectric loss measured at $1 \mathrm{kHz}$ are 1,164 and 0.063 , respectively, for $\mathrm{Ba} 0.5 \mathrm{Sr} 0.5 \mathrm{TiO} 3$ pellets calcined at $800{ }^{\circ} \mathrm{C}$ and sintered at $1,350{ }^{\circ} \mathrm{C}$. Leakage current density measured at $5 \mathrm{~V}$ for the $\mathrm{Ba} 0.5 \mathrm{Sr} 0.5 \mathrm{TiO} 3$ pellet was found to be $49.4 \mathrm{pA} / \mathrm{cm} 2$.
\end{abstract}

Keyword: Phase formation; Sol-gel technique; Dielectric; BST. 